\title{
Design and Implementation of the University Information Disclosure System Based on WeChat
}

\author{
Li-Zheng Jiang, Li-Yuan Han \\ School of control and Computer Engineering NCEPU, Beijing, China \\ E-mail: jianglizheng@eplian.com,947361040@qq.com
}

\begin{abstract}
Information disclosure WeChat public platform is aim to provide convenient conditions for schools open information. The platform is based on the information public network of North China Electric Power University. It provides real-time understanding of campus activities for school's teachers and students, users can apply to schools public in accordance with the application and it can also link to the address of the related information service website. The WeChat public platform uses Java EE SpringMVC architecture, prevalent MVC design patterns, jsoup web crawler to grab the web page, JSP output mobile phone page, jQuery Mobile for mobile phone page beautification and Sqlite lightweight database to save users' information.

This system mainly contains three parts of the function: Docking with the WeChat public platform, Submitting and reviewing the application form and grabbing data from school web site.
\end{abstract}

Keywords-wechat; public platform; information disclosure; spring $m v c$

\section{INTRODUCTION}

\section{A. Background}

WeChat is a free instant messaging service application for intelligent terminals, developed by Tencent Inc in January 21, 2011. WeChat can support cross communication operators and cross operating system platforms. It includes various functionalities such as instant messaging, real-time chatting, and social networking, and supports various message types such as text, voices, pictures, and videos. Compared with the traditional communication of mobile phone, and micro-blog, WeChat has obvious advantages. According to the Tencent official statistics, at the end of 2013, WeChat became an instant communication software with the largest mobile user groups in Asia, registered users of which exceeded 600 million. WeChat public platform is a new function module based on WeChat, which Tencent Inc officially launched on August 23, 2012. Through this platform, both individuals and organizations can create a WeChat public account to interact with fans, and obtain the group sending option and the powerful statistical functions. At present, WeChat public platform supports PC users, and uses can bind individual WeChat account to interact with fans by smart phone. On August 5, 2013, WeChat public platform was upgraded to divide the platform into the WeChat public service account and subscription account types. WeChat users can scan the two-dimensional code, search the account number or nickname to become fans of the WeChat public platform accounts, at the same time save and share messages.

\section{B. Significance of Project Development}

The popularity of smart phones and broadband Chinese strategy provide a wide prospect for mobile information service. Mobile phone users reached 500 million, accounted more than eighty percent of the total Internet users. Mobile phones remained the largest Internet terminal, and China Mobile Internet developed into the universal time. It had become the main Internet equipment of users to obtain instant information.

Information disclosure is a bridge between University and society. Modern university system requires colleges and universities to open education for the society in accordance with the law. Institutions of higher learning, either as an organization authorized by laws and regulations, or as an organization to provide public service, is in the use of national public resources to carry out activities, rather than the general private body, so they should maximize the provision of relevant information to the public and accept the supervision of the public. Besides, The service industry of popular higher education is constantly strengthened, market law intervention also requires universities must take into account the Higher Education's inherent logic and market logic, which can strengthen the exchange of information with the society and the market, form open school-running mode and enhance the competitiveness of the market. On the other hand, under the condition of knowledge economy, University personnel training, scientific and technological innovation, the transformation of achievements and social services show themselves fully to the society through information disclosure, which makes the universities to seek more selfdevelopment opportunities in the rapid development of economic society and maximize the efficiency of educational resources.

\section{FUNCTIONAL REQUIREMENTS ANALYSIS}

\section{A. System Function Analysis}

This system can help users pay attention to the dynamic information disclosure based on WeChat public service platform. This system mainly contains three parts of the function: Docking with the WeChat public platform, Submitting and reviewing the application form and grabbing data from school web site. Firstly, procedure needs to dock with the Wechat public platform, then create some menus and links. After the users follows the WeChat public 
accounts, they can view the school's dynamic information by clicking the menu buttons .

For this system, the dynamic information includes open list of the Ministry of Education, the school open list, secondary units open list and application. Procedures must ensure that docking with the WeChat public platform correctly, create the appropriate menu button, grab the data from the school website and create mobile pages for browsing the web. At the same time, we also need a management interface with WeChat platform that administrator can audit and reply application form.

This paper studies the information disclosure system based on the WeChat, the main achievement of the function is as shown in Figure1:

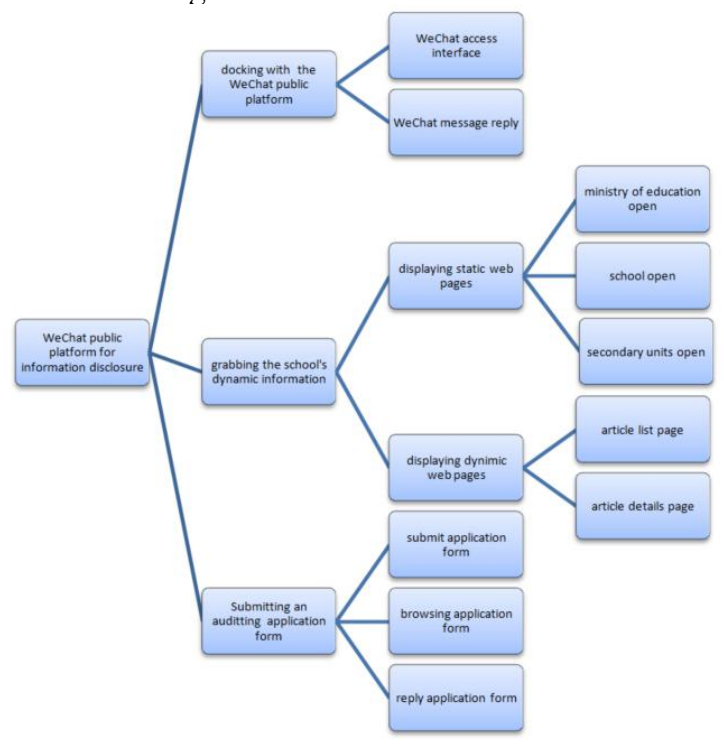

Figure 1.

Function module diagram.

\section{B. System Use Case}

Use case diagram as is shown in figure2:

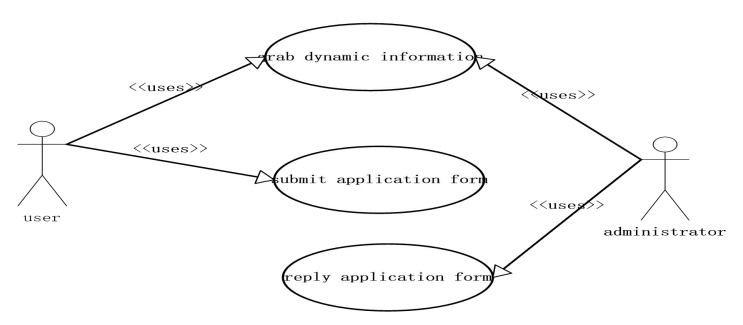

Figure 2. System use case diagram.

Use case diagram description:

Grab dynamic information: grab information from the school website constantly.

Submit application form: users submit application form based on WeChat.
Reply application form: administrator audit and reply users' application form.

\section{SYSTEM DESIGN}

\section{A. The Mode of Data Exchange on Wechat Public Platform Development}

Before the development of WeChat public platform, we have to understand the message exchange process, it is as shown in figure3:

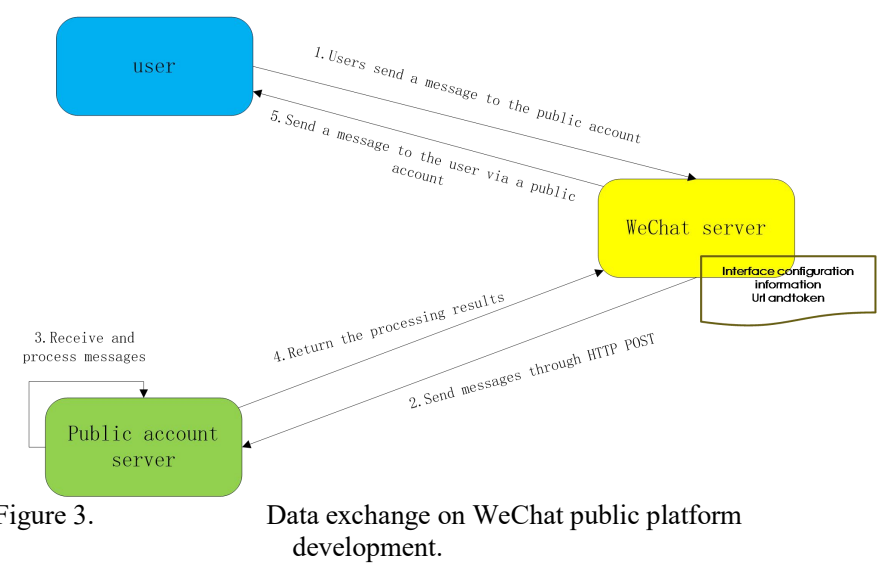

1) Users send a message to the public account through the WeChat client, the message is received by WeChat server.

2) After receiving the message, WeChat server will send messages to the public account server through HTTP POST, based on the URL that developer fill the interface configuration information.

3) After receiving the message, the public account server will process message according to the business logic.

4) After processing message, the public accounts will returned the processing results to the WeChat server.

5) WeChat server will send message to the user via a public account.

6) In the process of the whole message interaction, the public account server mainly does three things:

7) Receive message from WeChat server.

8) Process message according to the specified business logic

9) Return the results to the WeChat server.

\section{B. Access to WeChat}

WeChat development must be a developer model, and then access to WeChat according to the description of the developer's documentation, there are following steps:

1) Fill in server configuration: Need to provide the URL and Token two parameters to enable the "development mode". Moreover, URL must begin with "http://" and only supports 80 ports. Token arbitrarily filled by the developer, is used to generate a signature.

2) Verify message from the WeChat server: WeChat server sends a GET request to the URL when a public platform 
user submits these two parameters. And bring four parameters as shown in table I:

TABLE I. PARAMETER LIST

\begin{tabular}{|l|l|}
\hline \multicolumn{1}{|c|}{ Parameter } & Description \\
\hline Signature & WeChat cryptographic signature \\
\hline Timestamp & Timestamp \\
\hline Nonce & Random number \\
\hline Echostr & Random string \\
\hline
\end{tabular}

Developers confirm whether GET request comes from the WeChat server by checking the parameter "signature". If the check succeeds, return the parameter "echostr" as content, and then access into force, else access failure

3) Implement business logic based on interface documentation: Become a developer after Validation of the effectiveness of the URL. You can apply for WeChat certification in the public platform web site, and get more access to meet more business needs after the success of the certification.

\section{Design of System Architecture}

This system uses the traditional three layer B/S structure and links user show layer, business logic layer and data access layer. The business logic layer is that user access to the Http request, it uses Spring MVC's @Controller mark to achieve. Data access layer is the package module, using jsoup to grab data from the school web site and storing application forms information in the SQLite. The user show layer is mobile web pages, using the JSP and jQuery to beautify. System architecture is shown in figure4:

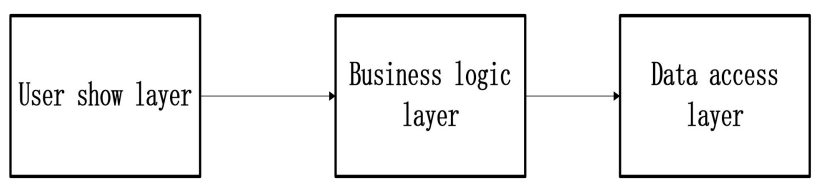

Figure 4. System architecture.

\section{Design of Database}

The application function requires the user to fill in the form under the guidance of the website, and upload the form. Then background administrators need to collect and audit the form submitted by the user.

The table in the corresponding database is shown in table2:

TABLE II. TAPPLICATION TABLE DESIGN

\begin{tabular}{|l|l|l|}
\hline \multicolumn{1}{|c|}{ Field name } & \multicolumn{1}{|c|}{ Data type } & Description \\
\hline Id & Int(AutoIncrement) & Unique identifier \\
\hline City & Varchar & Submitter's city \\
\hline Idnumber & Varchar & Submitter's ID card number \\
\hline Idphoto & Varchar & Photo's url \\
\hline Infocontent & Varchar & Information content \\
\hline Infouse & Varchar & Information usage \\
\hline Name & Varchar & Submitter's name \\
\hline Nickname & Varchar & submitter's WeChat nickname \\
\hline Opened & Varchar & WeChat openid \\
\hline Phonenumber & Varchar & Phone number \\
\hline Reply & Varchar & Administrator's message after auditing forms \\
\hline State & Tinyint & Submission Status \\
\hline Subtime & Timestamp & Submission time \\
\hline Work & Varchar & Submitter's work unit \\
\hline
\end{tabular}

\section{E. Design of Web Site Overall Configuration}

First, create a maven project in Eclipse, then eclipse will generate corresponding documents automatically. Maven project add the Java EE specification dependence in the pom.xml, introducing JSTL tag, SQLite JDBC connection, uploading files, jsoup crawlers and Spring jar package. Module named spring-webmvc, spring-web, jstl, Java EEapi,sl4j,jsoup,commons-fileupload and so on.

To integrate Spring MVC framework in a Java EE web project, the first step is to configure the web.xml file. Configuration in the web.xml includes the following content: $\log 4 \mathrm{j}$ listener listening logs, filtering coded character sets and configuration of spring MVC dispatcher servlet.

Configuring Spring MVC requires to create a file named spring-servlet. There are following configuration content: Bean Spring automatic scanning assembly, view explanation configuration of JSP, uploading file configuration, global exceptions, logging output, database connection and transaction package.

\section{SYSTEM IMPLEMENTATION}

Based on the above design for mobile information system based on the WeChat public platform, we complete the development and deployment of the system. The mobile terminal user interface of WeChat marketing platform is as shown in figure 5: 


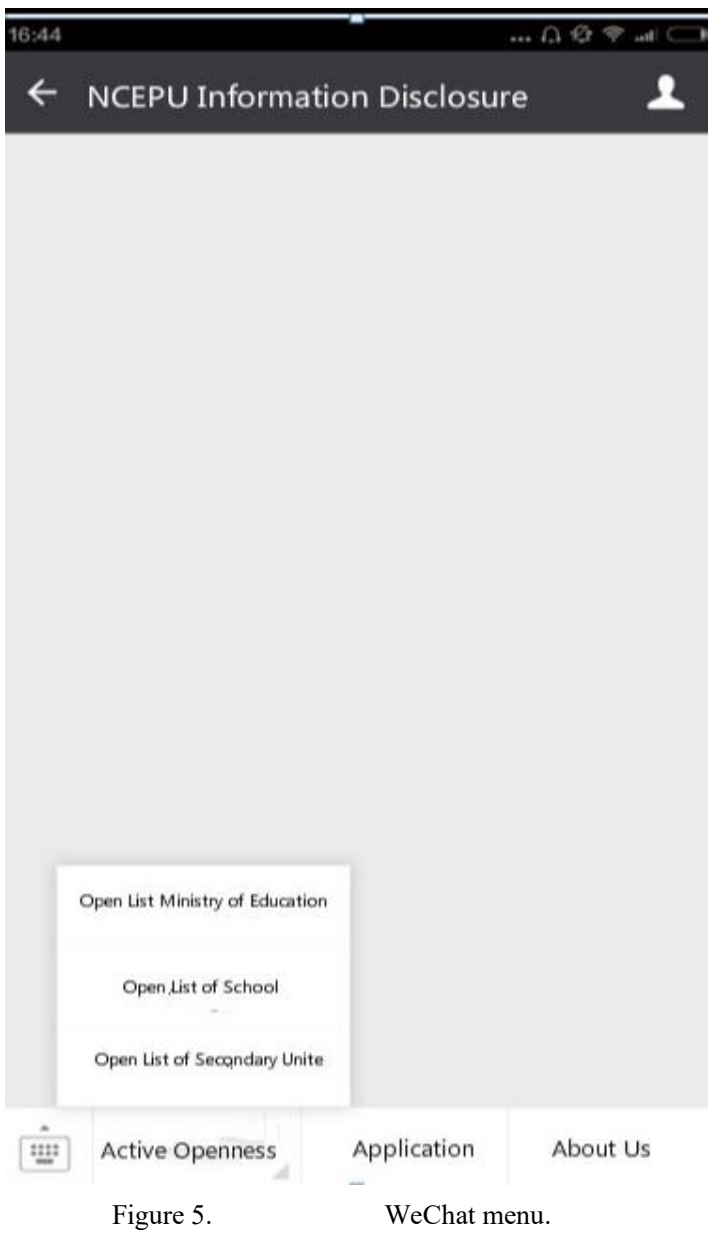

After creating the menu and linking to the response URL, we need to create the corresponding pages, open list page for the Ministry of education, open list page of the school and open list page of secondary units. As shown in figure 5:

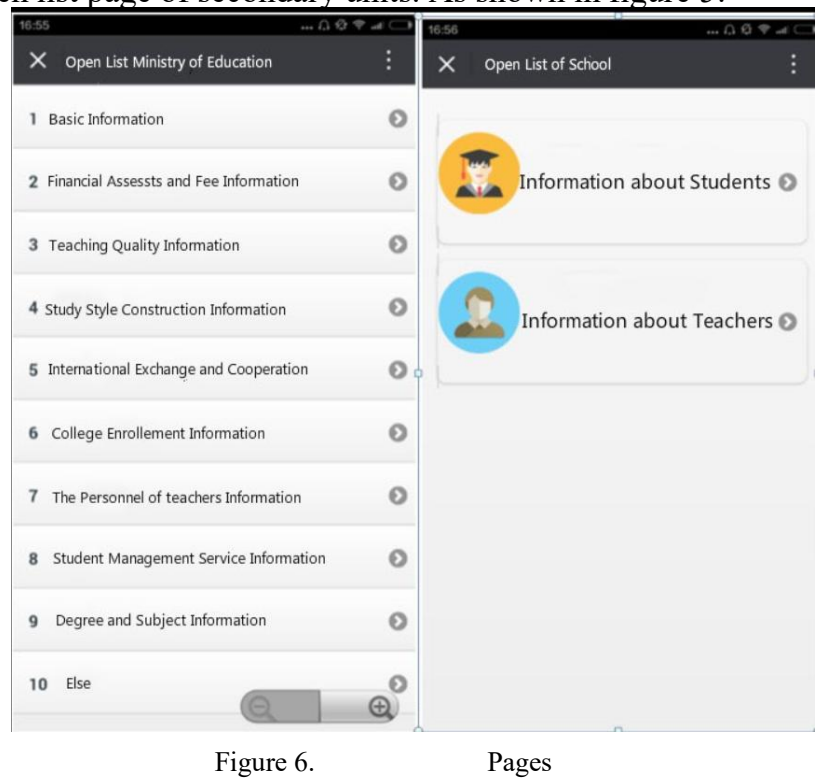

Figure 6.

Pages
Submitting and auditing the application form requires users to fill in and upload the form, then the background administrator need to collect and audit the form submitted by the user. Users click on the application with the browser to open the page as shown in Figure7:

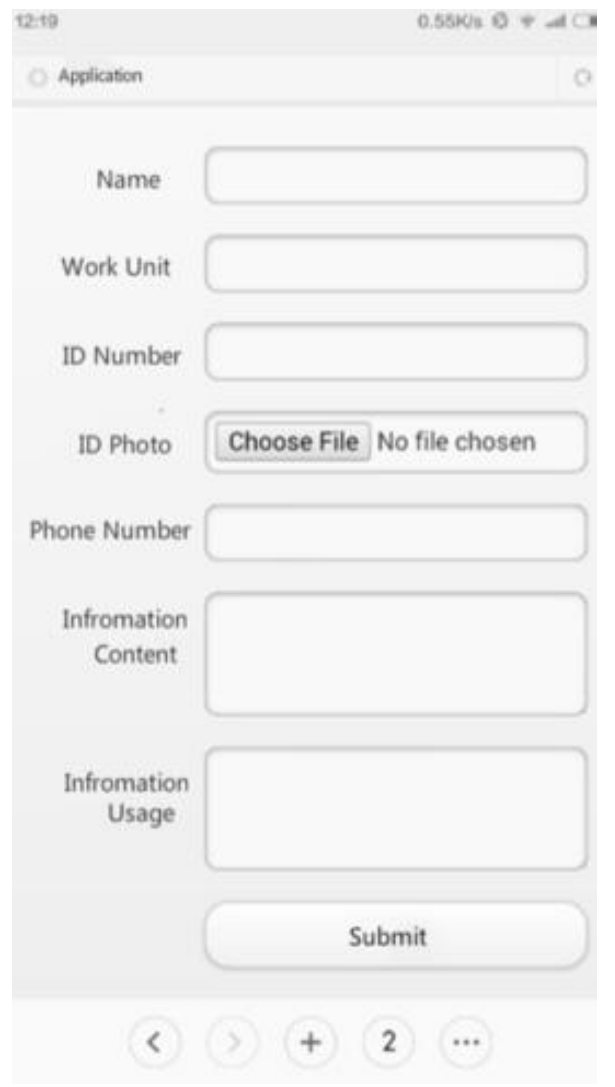

Figure 7. Application form.

\section{CONCLUSION}

Based on the study and analysis of existing mobile information service system, we proposed take advantage of WeChat public platform, a popular social networking platform, to design this mobile information system. The system is designed primarily to meet basic needs that the users browse information, and the main feature of the system is to make use of WeChat public platform, users do not need to install additional software and can be able to use this system just with WeChat on mobile devices. System has the characteristics of low coupling, cross platform, easy expansion and easy maintenance .

The development on WeChat is still evolving, public platform development are also continuing, We believe that there will be more and more forms of services which could use public platform with the passage of time. In conclusion, WeChat is worthy of sustained attention and research.

\section{REFERENCES}

[1] Zhao Jing and Li Bei. 2013." A preliminary study on the development of WeChat public platform", Journal Of News Practice. 
[2] Baidu Encyclopedia: http://baike.baidu.com/view/5117297.htm.

[3] Kaixiang Tan. 2014.The Design and Implementation of Ordering System Based on Wechat Pubilc Platform[D]Nanjing: Nanjing University

[4] Hui Xu .2014.Design and Implementation of Online Life Service Svstem based on Wechat.[D].Xi'an: Xi'an Electronic and Science University.

[5] Minzhi Guo. 2014.The Design and Implementation of Mobile Office System Based on Enterprise Wechat Account [D].Beijing: Beijing Jiaotong University
[6] Feng Liu. 2013.The development and application of WeChat public platform[M] .Beijing :China Machine Press

[7] H.P. Huang, W.H. He, Q. Ye. WeChat and Its Application in Library Information Service. Library Journal, 2013, (1), 62-64.

[8] Huang Lanfen and Huang Yaozhong. 2013. "The study of teachers interaction model system based on WeChat," Teacher Professional Development, 44-47.. 